\title{
Linguagem e comunicação em Heidegger
}

\author{
Fábio Fonseca de Castro
}

Resumo: O artigo discute a dimensão ontológica presente na categoria heideggeriana do "falar", procurando, a partir dela, construir uma interpretação da comunicação enquanto fenômeno fundamentalmente intersubjetivo. Para fazê-lo, utiliza-se o Heidegger de Ser e Tempo. Inicia-se explicitando a compreensão de Heidegger sobre a linguagem, presente nessa obra, para, em seguida, por meio dela, se alcançar a compreensão do filósofo sobre a comunicação. Procura-se demonstrar que o falar é equivalente a um dar sentido comum a algo: não o encontro, o revelar, do sentido próprio de algo, na sua pretensa dimensão ôntica, mas o sentido presente na intersubjetividade, no mundo compartilhado, nos recursos de compreensão que a pessoa lança mão na sua interação com outros. Assim, procura-se demonstrar que a reflexão filosófica sobre a linguagem e sobre a comunicação precisa se enraizar na ontologia do ser-com-outros para transpor os limites da metafísica do sujeito e da subjetividade e para alcançar uma compreensão profunda do fenômeno da intersubjetividade.

Palavras-chaves: intersubjetividade; comunicação; linguagem; Heidegger; fenomenologia.

Abstract: Language and communication in Heidegger - This article discusses the ontological dimension in the Heideggerian category of "talking," based on which we seek to make an interpretation of communication as a fundamentally intersubjective phenomenon. To this end, we use Heidegger's Being and Time. We begin by explaining Heidegger's concept of language, which he discusses in the above cited book, to gain an understanding of this philosopher's concept of communication. We seek to demonstrate that talking is equivalent to giving ordinary meaning to something: not the encounter, the revelation, of the meaning itself of something, in its so-called ontical dimension, but the meaning present in intersubjectivity, in the shared world, and in the resources of understanding that the individual uses in his interactions with others. Based on this rationale, we seek to demonstrate that philosophical reflections about language and communication should be rooted in the ontology of being-with-others in order to go beyond the bounds of the individual's metaphysics and of subjectivity in order to gain a deeper understanding of the phenomenon of intersubjectivity.

Keywords: intersubjectivity; communication; language; Heidegger, phenomenology. 
A teoria da linguagem de Heidegger consiste numa desconstrução da ideia de Sujeito - e, portanto, de subjetividade - por meio da denúncia de que a trajetória do pensamento ocidental, com um ápice que se situa na modernidade cartesiana e que se reproduz incessantemente até nossos tempos, esqueceu tanto a questão sobre a linguagem como, simplesmente, a própria linguagem.

Sim, há um paradoxo aí, perceptível quando lembramos que as teorias da linguagem constituem, ao se produzirem como um jogo de relações entre significados e significações, um produto fundamental do pensamento moderno. Porém, esse paradoxo só tem sentido quando colocamos o problema da linguagem de maneira ôntica, como se a linguagem fosse externa ao sujeito - e como se houvesse sujeito da linguagem ou mesmo sujeito... Quando colocamos a questão ontologicamente - ou seja, em sua dimensão reflexiva - como propõe Heidegger, vemos que é o Ser que está na linguagem, que habita um mundo já ocupado pela linguagem. E isso se dá porque esse Ser reflexivo que somos é, na verdade, não um "indivíduo", não um "Eu", não um "Ego", mas um inter-sujeito, um ser-aí, um ser-no-mundo, um ser-com-outros. Um ser intersubjetivo, em resumo.

O Ego, para Heidegger, não equivale ao Ser. E, muito menos ao Ser do Dasein, o Ser-aí, que somos, jogados no mundo sem nenhuma explicação e que encontramos uma linguagem já existindo. Meschonnic (1990) bem sintetiza a oposição: "Je, à lui seul, porte la pratique et la théorie de la modernité. La cohérence du langage Heidegger fait à la fois I'anti-modernité et l'anti-langage. (...) L'être est l'anti-sujet absolu". . E observa, para concluir, que "au Je de Benveniste s'oppose l'être de Heidegger"1 (MESCHONNIC, 1990, p. 185).

De fato, o problema da linguagem é uma constante na reflexão de Heidegger. Ele já se encontrava, de maneira central, no seu curso de 1925, intitulado Prolegômenos à história do conceito de tempo - no qual o filósofo afirma que "há linguagem porque há o falar" (HEIDEGGER, 1976, p. 214); atravessa Ser e Tempo, onde a linguagem figura como "o pronunciamento do falar" (HEIDEGGER, 1976, p. 216) e prossegue na obra de maturidade, por meio da formulação da questão da Kehre, a "virada", e do ensaio Die Sprache (HEIDEGGER, 1972).

Embora, nesse momento, a compreensão heideggeriana da linguagem se desloque para uma indagação sobre a possibilidade de converter o significado em significante (BOTET, 2010, p. 59). Nesse ensaio, por meio da noção de Unter-Schied - que Derrida (2009) compreenderá como differance - Heidegger ensaia perceber o "texto" sem fronteirizações inerentes: tudo sendo movimento, o que provoca um redireccionamento da teoria da linguagem presente em Ser e Tempo, aqui discutida.

Botet (2010) indica a possibilidade de ler Ser e Tempo como uma aporia "consistant à vouloir d'un côté faire du langage et de la langue des dérivés ontológico-existentiaux

1 Nossa tradução: "(a noção de) Eu, por si mesma, porta a prática e a teoria da modernidade. Heidegger faz (da ideia de coerência) da linguagem, ao mesmo tempo, a anti-modernidade e a anti-linguagem (...) O Ser é o anti-sujeito absoluto" e "À ideia de Eu, de Benveniste, se opõe a ideia de Ser, de Heidegger". 
du Dasein, et de l'autre manifester ce Dasein à l'aide d'une langue determinée"2 (ibid., p. 8) e, em paralelo, como uma tentativa de desconstrução da linguagem metafísica (ibid., p. 8) razão que motiva a profusão de neologismos empregados - e que fracassará, afinal, quando Heidegger constatar o enfeudamento, pela linguagem metafísica, de todas as possibilidades de enunciação do Ser, por meio de representações espacializantes (ibid., p. 8) ${ }^{3}$.

Embora a linguagem esteja, implicitamente, no cerne da questão heideggeriana, sobre o Ser, em Ser e Tempo - já que encontrar o sentido pressupõe o uso da linguagem, e não de qualquer linguagem, mas de uma própria, que não tenha sido contaminada pela metafísica tradicional (Cf. HEDEIGGER, 1976, § 7) - e, assim, seja enunciada, indiretamente, desde as primeiras páginas do livro, é no capítulo $V$ dessa obra, intitulado "Das In-Sein als Solches" (O ser enquanto tal) em que vamos encontrar, especificamente, a discussão sobre o tema. No § 34, nesse capítulo, intitulado "Da-sein und Rede. Die sprache" (O Dasein e o falar. A linguagem.), o filósofo reflete, especificamente, sobre o estatuto existencial da linguagem.

No desenvolvimento dessa questão, Heidegger constrói duas teses: a de que o fundamento ontológico-existencial da linguagem é o falar e a de que o falar (Rede) é cooriginário com os outros dois existenciários que permitem a abertura do Dasein: a afectação (Befindlichkeit), ou melhor, o sentimento de participação numa dada experiência, e o compreender (Verstehen) ${ }^{4}$.

A primeira tese pode ser resumida na ideia de que a linguagem não é preexistente ao falar, não é algo que está no mundo e que será usada, como um dispositivo do qual a pessoa vai se servir. A linguagem não antecede ao seu uso. É por isso que o discurso, ou melhor, o falar, tal como entendido por Heidegger, designa não um comportamento linguístico, mas a condição ontológica de possibilidade de todo comportamento linguístico (ROMANO, 2008). Em síntese, existe linguagem porque existe discurso - "Es gibt Sprache, weil es Rede gibt" - e não o contrário, qual normalmente se pensaria - como coloca Heidegger nos Prolegomena zur Geschichte des Zeitbegriffs (HEIDEGGER, 2006, p. 383).

Essa ideia é mais bem compreendida quando lembramos que, no § 31 de Ser e Tempo, Heidegger apresentara a noção de compreensão (Verstehen) por meio da ideia de que o sentido, ontologicamente, é precedido pela ação de compreender. O que entendemos aqui por o falar é equivalente ao que aqui entendemos por sentido. Não o sentido próprio da coisa - ou seja, sua pretensa dimensão ôntica -, mas o sentido presente na intersubjetividade, no mundo compartilhado, nos recursos de compreensão que a pessoa, o Dasein, vai lançar mão na sua interação com outros.

2 Nossa tradução: "Consistindo a desejar, de um lado, fazer da linguagem e da língua derivados ontológicosexistenciais do Dasein e, de outro, manifestar esse Dasein por meio de uma língua determinada".

3 É essa constatação que fará de Ser e Tempo uma obra inacabada e que produzirá a célebre "virada" (Khere) de 1935, com seu ensaio sobre a obra de arte, Der Ursprung des Kunstwerkes, constante de Holzwege (Heidegger, 1986).

4 Existenciários são, em Heidegger, mecanismos, portas, por meio dos quais o Dasein vislumbra encontrar algum sentido, alguma resposta, para sua existência. 
Pelo falar, o Dasein se exprime, e ele não o faz porque possua um "interior" separado de um "exterior", mas porque, sendo-no-mundo, ele já está, permanentemente, fora de si (HEIDEGGER, 1976, p. 215-216). É nesse sentido que Heidegger define o falar como a articulação da compreensão do ser-no-mundo com seu sentimento de situação, a sua facticidade. Isso nos remete à segunda tese mencionada, que reproduz a abordagem fenomenológico-existencial de Heidegger, o método geral que move Ser e Tempo.

Segundo o filósofo, o falar é, existencialmente, cooriginário com a facticidade - mais especificamente, com o sentimento de situação, ou a experiência facticial (Befindlichkeit) e com a compreensão (Verstehen): "Die Rede ist mit Befindlichkeit und Verstehen existential gleichursprünglich"5 (HEIDEGGER, 1976, p. 213). Ou seja, o falar não surge independentemente de um sentimento de estar-no-mundo e de um processo de compreensão: é simultâneo a eles. Existindo antes da linguagem, ele se torna linguagem nesse ato conjunto que agrega os três existenciários para ser pronunciado, ganhar existência comum, tornar-se mundo e, assim, produzir a linguagem. Pronunciado, o falar se torna linguagem. Pronunciado, ele "existe": falar é existir, "die Rede ist existenzial Sprache"6 (HEIDEGGER, 1976, p. 214).

Em outros termos: Eu sou aquilo que digo. Pode-se, assim, compreender o Dasein como um ser falante, um discursivo, o que não quer dizer, simplesmente, que ele é um ser capaz de articular a linguagem: mais que isso, a sua faculdade realmente significativa é a de articular aquilo que compreende. Articulando a sua compreensão por meio da sua discursividade, o Dasein "met en rapport les unes avec les autres les possibilités et la situation que lui révèlent le comprendre et la disposition"7 (BOUTOT, 1989, p. 31).

A segunda tese afirma que o falar é cooriginário com a afectação e com o compreender, mas, no seu desenvolvimento, também afirma que a linguagem se situa após a compreensão (Verstehen) e a explicitação (Auslegung) ${ }^{8}$. O que isso quer dizer? Na verdade, se trata de uma sequência óbvia da primeira ideia: a ação de compreender leva, naturalmente, à ação de explicitar o compreendido; trata-se de um caminho natural na formação do sentido, compreendendo-se sentido por algo que é estruturado pelo processo comum, simultâneo - cooriginário - de encontrar-se diante de algo (facticidade), compreender, explicitá-lo e dizê-lo, em pensamento, discurso, ação. Segundo Heidegger, "Sinn ist das durch Vorhabe, Vorsicht und Vorgriff strukturierte Woraufhin des Entwurfs, aus dem her etwas als etwas verständlich wird" (HEIDEGGER, 1976, p. 201)9.

5 Nossa tradução: "O discurso é cooriginário que a facticidade e o compreender".

6 Nossa tradução: "O falar é, existencialmente, linguagem".

7 Nossa tradução: "coloca em relação, umas com as outras, as possibilidades e a situação que lhe revelam o compreender e a afectação".

8 Literalmente, traduz-se Auslegung por "interpretação". Optamos por trabalhar com a ideia de "explicitação" porque acreditamos que ela se acorda melhor ao pensamento de Heidegger, à medida que o autor se refere a um procedimento banal e quotidiano, próprio a qualquer pessoa, e não a um conhecimento produzido por especialistas, tal como o termo "interpretação" pode levar a crer.

9 Nossa tradução: "O sentido é esse sobre-o-quê estruturado pela pre-ocupação, pela pre-visão e pela pre-concepção por meio das quais ele se estrutura como projeto. É a partir disso que algo se torna compreensível como algo". 
Na sua ação quotidiana de compreensão, o Dasein não tem, necessariamente, consciência de que está compreendendo. Ele se projeta em direção de suas possibilidades sem, a todo o momento, saber-se se projetando dessa maneira. Porém, algumas vezes, ele adquire essa consciência; é como se nos disséssemos: "não estou compreendendo bem isto aqui", ou "agora vou fazer um esforço de compreensão" ou ainda "tenho aqui um problema de compreensão".

Nesses momentos, tem-se a explicitação (Auslegung), a ideia de que na explicitação, o compreender não se torna outra coisa, mas sim ele mesmo (HEIDEGGER, 1976, $\S 32$ ). É a explicitação, portanto, um compreender mais profundo, não no sentido de um compreender especializado, bem entendido, mas no sentido de um compreender reflexivo.

É precisamente essa dimensão reflexiva que permite perceber o problema heideggeriano da linguagem, pensado como problema comunicativo.

Heidegger diferencia a comunicação enquanto fenômeno ôntico da comunicação enquanto fenômeno ontológico. Onticamente, comunicação é, simplesmente, Mitteillung, falar com o outro. Ontologicamente, comunicação equivale ao sentido, ao sentido percebido como a experiência de se compreender alguma coisa de tal maneira. E assim, portanto, à intersubjetividade. Estamos atrás, aqui, dessa compreensão ontológica da comunicação.

É importante esclarecer que Heidegger não emprega o termo intersubjetividade em Ser e Tempo e que, quando mencionamos uma "noção heideggeriana de intersubjetividade", estamos nos referindo à problemática do ser-com-outros (Mitsein), enunciada no $\S 26$ do livro, discutida no tópico seguinte e retomada mais à frente, no conjunto dos $\S \S 58$, 60 e 74, no contexto da distinção entre caráter autêntico e caráter inautêntico do Ser.

Com base nessa compreensão, podemos colocar que o tema da intersubjetividade constitui uma preocupação maior de Heidegger, à medida que conforma o contexto no qual, ao mesmo tempo, se processa sua crítica do subjetivismo e da identidade e a sua compreensão do caráter participativo - se assim podemos dizer - do Dasein, pois como se viu, Heidegger elabora, por meio de sua apresentação ontológica da linguagem, uma crítica da metafísica do sujeito e da subjetividade.

Essa crítica, pensada do ponto de vista dos processos comunicativos, leva-nos a perceber que a comunicação não é, ela também, o simples jogo de interações entre consciências individuais que se colocam em diálogo. Mais que isso, ela é uma dinâmica intersubjetiva, que se constitui no falar. A comunicação, seguindo a mesma dinâmica, não é, assim, preexistente ao falar, ela não antecede ao seu uso. O fundamento ontológicoexistencial da comunicação é o falar, e não a linguagem ou a consciência/inconsciência discursiva de "sujeitos". Da mesma maneira, a comunicação é, pode-se dizer, um fenômeno que se produz na simultaneidade desses três existenciários, que são o falar (Rede), a afectação (Befindlichkeit) e o compreender (Verstehen).

As duas teses sobre a linguagem expostas no $§ 34$ de Ser e Tempo são fundamentais para que se compreenda a noção heideggeriana de intersubjetividade e, portanto, 
da comunicação. Por extensão, podemos pensar no problema heideggeriano da linguagem enquanto problema comunicativo.

Pensamos que os termos comunicação e intersubjetividade são, efetivamente, análogos. Pensar em comunicação fora da sua dimensão ontológica resulta num encobrimento da questão sobre o que é, realmente, o fenômeno da comunicação. Não se trataria, necessariamente, de um procedimento ou de resultados incorretos, mas, com efeito, seria um procedimento que, de partida, deixa-se envolver pela experiência metafísica, chegando a resultados que, com sua predisposição ôntica, distanciam-se do fenômeno próprio da comunicação.

Revenhamos, então, a ele. O fenômeno próprio da comunicação é a intersubjetividade. Por tal, devemos compreender aquilo que é "existencialmente significante"; ou melhor, aquilo que pressupõe um estar-no-mundo, que é, ao mesmo tempo, por extensão, um estar-com-outros, pois o falar, que precede a linguagem e que é simultâneo à facticidade e à compreensão, exprime um ser-em-comum. O Dasein não é um "sujeito", é um ser-aí-no-mundo, um ser-aí-com-outros. Ele não é uma "subjetividade" ou um efeito de "consciência", mas sim a materialidade da dimensão ontológica de toda pessoa. Como interpreta Greisch,

Existentielement parlant, nous ne nous trovons jamais dans la situation fictive où nous serions déjà en possession d'un signifiant (Wörterding), qui s'agissait d'allouer (zulegen) à un signifié non encore trouvé. Au contraire, les significations sont déjà là; eles nous habitent déjà (à titre d'affections ou de comprehensions ou d'explicitations) et puis, tout à coup, nous viennent les mots pour les dire..$^{10}$ (GREISCH, 1994, p. 206)

Isso se dá porque o fenômeno da linguagem e, em consequência, da comunicação, tem suas raízes "in der existentialen Verfassung der Erschlossenheit des Daseins sein Wurzeln hat"11 (HEIDEGGER, 1976, p. 160). É por isso que a linguagem "existencialmente significante" se opõe à linguagem puramente formal, abordada onticamente. Ser existencialmente significamente pressupõe um estar-no-mundo que é, ao mesmo tempo, um estar-com-outros: a intersubjetividade. O falar, que precede a linguagem, assim, exprime um ser-em-comum.

Linguagem e comunicação são manifestações do falar. Mas enquanto a linguagem é vista por Heidegger como a extensão do falar, a comunicação é apresentada como o sentido acumulado pela própria experiência do falar - portanto, como experiência

10 Nossa tradução: “Existencialmente falando, nós não nos encontramos, jamais, na situação fictiva na qual já estaríamos em possessão de um significante (Wörterding), que poderia se vincular a um significado ainda não encontrado. Ao contrário, as significações já estão lá; elas habitam em nós (enquanto afeições ou compreensões ou explicitações) e assim, instantaneamente, nos vêm as palavras para dizê-las".

11 Nossa tradução: "(tem raízes) na composição existencial da abertura do Dasein" 
intersubjetiva. Ontologicamente, tal como o falar precede a linguagem, a comunicação precede a palavra, o "dito". Pasqua o afirma quando escreve que "ontologiquement, la communication est déjà là, ele fait partit du mouvement par lequel le Dasein sort toujours de soi pour ek-sister ver autrui. La communication n'est donc pas créée par des paroles, ele les precede"12 (PASQUA, 1993, p. 78).

Gelven caminha na mesma direção, quando diz que,

Language is communication; but it is a communication that is already there; it is something we use to make explicit our talking. Talking is a sharing which is always more than what is represented by the explicit verbalization of word language. (...) The point is that a reader of a well written dialogue, for example, does not read only words. He contributes his own "talk" when he reads. This mean that he involves himself, not a mere viewer of the words on the page, but as a fellow human being for whom the spoken words excites the existential response necessary for talk..$^{13}$ (GELVEN, 1989, p. 105)

Compreende-se que, em Heidegger, comunicação constitui o sentido intersubjetivamente construído - aqui uma vez mais vale ressaltar: não o sentido do ente, da coisa, do referido, mas o sentido acumulado pela experiência do Dasein no seu ser-com-outros, ser-no-mundo. Em Heidegger a noção de sentido é absolutamente simples e chega a parecer simplória (GELVEN, 1989, p. 98).

O sentido de uma coisa é a coisa mesma - jamais a palavra que demonstra a coisa, embora, evidentemente, as palavras sejam igualmente coisas, entes, que também estão no mundo. Trata-se, aqui, de compreender o sentido por meio do caráter ontológico do estar-no-mundo, evitando o primado ôntico no juízo das interpretações, que leva à sugestão de que todo sentido é mediado por estruturas significantes. O sentido de um beijo é o afeto (GELVEN, 1989, p. 98). O sentido jamais está na palavra, mas no Dasein: "Meaning (...) is a part os Dasein's 'here' in general 'Being here in the world'" (ibid., p. 98).

Procurando explicar essa relação, Gelven relaciona os quatro pontos centrais da teoria de Heidegger sobre o sentido:

1. Meaning refers to a condition of Dasein, not to words or sentences.

2. Meaning is the result of the projection of possibilities in terms of as-structure.

3. Meaning takes its ultimate ground from the world as ready-at-hand (zuhanden) rather than present-at-hand (vorhanden).

12 Nossa tradução: "ontologicamente, a comunicação já está aí, ela faz pate do movimento por meio do qual o Dasein sai de si, continuamente, para ek-sistir na direção do outro. Assim, a comunicação não é criada por palavras; ela as precede".

13 Nossa tradução: "Linguagem é comunicação, mas é uma comunicação que já estava ali; é alguma coisa que usamos para explicitar nossa fala. Falar é uma troca que contém sempre mais do que aquilo que é representado pela verbalização explícita da linguagem. (...) O ponto é que o leitor de um diálogo bem escrito, por exemplo, não apenas lê as palavras. Ele contribui com a sua própria 'fala', enquanto está lendo. Isso significa que ele não é um mero espectador das palavras que estão na página que lê, mas um ser humano, para quem as palavras ali presentes motivam uma resposta existencial, provocada pelo diálogo". 
4. Verbal meaning is a derivative form of existential meaning..$^{14}$ (GELVEN, 1989, p. 100)

Tem-se aqui o pressuposto fenomenológico da intencionalidade do sentido. O sentido se produz enquanto intenção comunicativa. A respeito disso, é oportuno observar o pensamento de Drogett, para quem

O processo de comunicação está relacionado diretamente com a intenção comunicativa que, funciona nesse caso, como um estímulo, uma espécie de poética da vontade que desemboca consequentemente numa poética da ação, na medida em que a práxis comunicativa, mais do que um simples querer, supera a tradicional antinomia entre sujeito e objeto. (DROGETT, 2005, p. 25)

Para esse autor, na sua leitura de Heidegger, a possibilidade da comunicação está no posicionamento do sentido para além do caráter evanescente e fugaz do acontecimento discursivo. É quando o falar se torna mais do que um acontecimento, conformando-se como sentido, que se estabelecem as condições de possibilidade da comunicação (ibid., p. 26).

Heidegger assinala que em todo falar, há uma falar-enquanto-tal e um falar comunicativo. O falar-enquanto-tal equivale à comunicação entendida onticamente (Mitteilung), ou seja, aquilo que o falar propaga. Já no falar comunicativo se tem a própria experiência ontológica do ser-com-outros (Mitdasein), que permite o sentido:

Das Phänomen der Mitteilung muß, wie schon bei der Analyse angezeigt wurde, in einem ontologisch weiten Sinne verstandem warden. Aussagende 'Mitteilung', die Benachrichtigung zum Beispiel, ist ein Sonderfall der existenzial grundsätzlich gefaßten Mitteillung. In dieser konstituiert sich die Artikulation des verstehenden Miteinanderseins. Sie vollzieht die 'Teilung' der Mitbefindlichkeit und des Verständnisses des Mitseins. ${ }^{15}$ (HEIDEGGER, 1976, p. 215)

Essa percepção questiona, a fundo, toda compreensão de comunicação como fenômeno exterior ao indivíduo intersubjetivo - a base, podemos identificar claramente, de todo o conjunto teórico da comunicacão, esteja ele nas tradições funcionalistas ou críticas, semióticas ou culturológicas e tanto na noção de mediação como na de midiatização -, um debate que se abre e que pretendemos abordar em outro trabalho. É uma percepção centrada na ideia de que o Dasein - o Ser-aí, é, necessariamente, também,

14 Nossa tradução: "1. O sentido se refere a uma condição do Dasein, e não a palavras ou a sentenças. 2. O sentido é o resultado da projeção de possibilidades em termos de estruturas. 3 . O sentido tira seu fundamento último do mais do mundo-tal-como-está-a-mão (zuhanden) de que do presente-como está-a-mão. 4. O sentido verbal é uma forma derivativa do sentido existencial".

15 Nossa tradução: "O fenômeno da comunicacão deve, tal como foi indicado na análise, ser compreendido em um sentido ontologicamente largo. Uma comunicação 'enunciativa', um 'comunicado', por exemplo, é um caso particular da comunicação produzida existencialmente de maneira fundamental. É nessa comunicacão que se constitui a articulação do ser-com-outro compreensivo. É ela que realiza a partilha da co-afectação e da co-compreensão do ser-com-outros". 
um ser-com-outros. A comunicação se conforma como processo de co-partilha, por meio do falar, de outras co-experiências: a co-afectação e da co-compreensão.

Voltamos aqui à tese de que o falar é, existencialmente, cooriginário com a facticidade - mais especificamente, com o sentimento de situação, ou a experiência facticial (Befindlichkeit) e com a compreensão (Verstehen). Por isso, no trecho referido, o uso das expressões co-afectação (Mitbefindlichkeit) e co-compreensão (Verständnisses). Pensar a comunicação enquanto co-partilha exige superar todo resquíscio de comunicacão enquanto informação, enquanto transporte:

Mitteilung ist nie so etwas wie ein Transport vor Erlebnissen, zum Beispiel Meinungen und Wünschen aus dem Innerem des einen Subjekts in das Innere des anderen. Mitdasein ist wesenhaft schon offenbar in der Mitbefindlichkeit und im Mitverstehen. Das Mitsein wird in der Rede "ausdrücklich" geteilt, das heißt es ist schon, nur ungeteilt als nicht ergriffenes und zugeeignetes ${ }^{16}$ (HEIDEGGER, 1976, p. 215).

Não sendo o mero transporte de vivências, opiniões ou desejos, a comunicação resulta numa coexperiência que acontece, mesmo quando não é, por assim dizer, apreendida ou apropriada.

A noção de intersubjetividade - e, em nosso modo de ver, a compreensão da comunicação, enquanto fenômeno intersubjetivo, - decorre da compreensão, de Heidegger, de que a comunicação deve ser compreendida a partir da estrutura do Dasein como ser-com-o-outro, com a consequência de que uma análise ontológica da linguagem ou da comunicação devam ser, necessariamente, uma análise da coexistência.

Dizendo de outro modo, a reflexão filosófica sobre a linguagem e sobre a comunicação precisa se enraizar na ontologia do Dasein para transpor os limites da metafísica do sujeito e da subjetividade e para alcançar uma compreensão da intersubjetividade que a tenha não como, meramente, a interconexão entre diferentes subjetividades, mas como a coexistência - evocando o uso do termo em sua origem semântica, na qual ek-sistir tem o sentido de projetar-se, de si para fora. A comunicação, enquanto condição ontológica do Dasein, consiste na sua possibilidade de coexistência.

Fábio Fonseca de Castro é pós-doutor pela Université de Montréal e doutor em sociologia pela Université Paris 5 (Sorbonne-Descartes).

fabio.fonsecadecastro@gmail.com

16 Nossa tradução: "A comunicacão não é, jamais, algo como o transporte de vivências, de opiniões e de desejos, por exemplo, do interior de um sujeito para o interior de um outro. O ser-aí-com-outros está, essencialmente, já manifesto na co-afectação e na co-compreensão. O ser-com-outros, no falar, é 'expressamente' partilhado, o que quer dizer que ele já está partilhado, mesmo quando não é apreendido ou apropriado". 


\section{Referências}

BOTET, Serge (2010). L'ontologie de la langue chez le dernier Heidegger. Strasbourg, Presses Universitaires de Strasburg.

BOUTOT, Alain (1989). Heidegger. Paris, PUF.

DERRIDA, Jacques (2009). A escritura e a diferença. Lisboa, Perspectiva.

DROGUETT, Juan (2005). A verdade no fenômeno da comunicação. Revista Imes Comunicação, v. 5 , n. 10 , jan/jun.

GELVEN, Michael (1989). A commentary on Heidegger's Being and Time. DeKalb, Northern Illinois University Press.

GREISCH, Jean (1994). Ontologie et temporalité. Esquisse d'une interprétation intégrale de Sein und Zeit. Paris, Presses Universitaires de Frances.

HEIDEGGER, Martin (1972). Die Sprache. Tübingen, Max Niemeyer Verlag.

(1976 [1927]). "Sein und Zeit". In: Gesamtausgabe. Frankfurt, Vittorio Klostermann, II vol.

(2006). Prolégomènes à I'histoire du concept de temps. Tradução para o francês de Alain Boutot. Paris, Gallimard, p. 383.

MESCHONNIC, Henri (1990). Le langage Heidegger. Paris, PUF.

PASQUA, Hervé (1993). Introduction à la lecture de Être et temps de Martin Heidegger. Lausanne, L'Age d'Homme.

ROMANO, Claude (2008). Une autre tradition sémantique? Heidegger, Bühler et l'ombre de Wittgenstein. Po\&sie, n, 122-123. 